\title{
Problems and Countermeasures of Transformation and Innovation of Scientific and Technological Resources in Colleges and Universities - A Case Study of Guangdong-Hong Kong-Macao Greater Bay Area
}

\author{
Jian Dong ${ }^{1}$, Jianru Xie ${ }^{2}$, Guizhen $\mathrm{Fu}^{3, *}$ \\ ${ }^{1}$ School of Management, Guangdong Food and Drug Vocational College, Guangzhou, China \\ ${ }^{2}$ School of Accounting Department, Guangdong Polytechnic of Water Resources and Electric EngineeringEnter, \\ Guangzhou, China \\ ${ }^{3}$ Department of Art and Design, Guangdong Industry Polytechnic, Guangzhou, China \\ *Corresponding author. Email: 99119834@qq.com
}

\begin{abstract}
Based on the connotations and characteristics of the scientific and technological resources in colleges and universities, this paper proposes that there are a large number of problems in the colleges and universities in the Guangdong-Hong Kong-Macao Greater Bay Area, such as the lack of the government-industry-university-research collaboration, the dispersion of the scientific and technological resources, the low sharing degree, and the imperfect promotion mechanism for the transformation of the scientific and technological achievements. It also profoundly analyzes the current situation and problems of the scientific and technological resources in colleges and universities, and finally proposes the countermeasures to optimize the transformation of the scientific and technological resources in the colleges and universities in Guangdong-Hong Kong-Macao Greater Bay Area.
\end{abstract}

Keywords: Colleges and universities; transformation of the scientific and technological resources; problems and countermeasures

\section{INTRODUCTION}

The collective term, the scientific and technological resources, refers to the human resources, the material resources and the financial resources in the process of the activities of scientific research, as well as the organizations, the management, the information and other software and hardware elements. It is the basis of scientific and technological innovation activities and plays a fundamental role in enhancing the capacity of independent innovation and building an innovative country. In the Outline Development Plan for the Guangdong-Hong Kong-Macao Greater Bay Area, it is proposed that "to implement the innovation-driven development strategy in great intensity, deepen innovation cooperation among Guangdong, Hong Kong and Macao, build an open community for coordinated innovation in the region that encompasses integrated development, pool together international innovation resources, enhance the innovation system and policy environment, focus on enhancing the capability for the commercial application of technological achievements, and develop a focused area of global technological innovation and a major source of emerging industries." The scientific and technological resources in colleges and universities are important in China's scientific and technological resources. How to reasonably and fully perform the overall sharing of the scientific and technological resources in colleges and universities so as to serve scientific and technological innovation and produce value-added effects should become a question for university administrators and scientific and technological workers to consider[1].

\section{AN OVERVIEW OF THE SCIENTIFIC AND TECHNOLOGICAL RESOURCES IN COLLEGES AND UNIVERSITIES}

The scientific and technological resources in colleges and universities refer to all the scientific resources and technological resources that are directly 
or indirectly needed in the scientific and technological activities in colleges and universities, and which constitute the production factors with the selectivity of development and utilization, as well as the sum of the resources that intersect with science and technology. The scientific and technological resources mainly have the following characteristics:

\subsection{Scientific and Technological Resources Are in Close Combination with the Talent Cultivation in Colleges and Universities}

The scientific and technological resources in colleges and universities are both educational resources and scientific and technological resources, and they are also the combination of talent cultivation and scientific and technological resources. The overall sharing ability of the scientific and technological resources in colleges and universities affects the effects of talent training and the ability of the scientific and technological innovation of colleges and universities.

\subsection{There Are Multi-Level and High-Quality Human Resources for the Scientific and Technological Innovation in Colleges and Universities}

There are multi-level faculties from lecturers to professors in colleges and universities. The subjects are distributed in many fields, and a multi-level system of talent training from specialists to doctoral students has been established, which endows the talent resources of scientific and technological innovation in colleges and universities with multi-level and high-quality characteristics.

\subsection{There Are Advanced Experimental} Facilities, Equipment, Sites and Library Information Resources in Colleges and Universities

Based on their own advantages of disciplines, professional laboratories at different levels have been established and approved in the colleges and universities of China, with advanced apparatus, equipment and experimental sites, as well as rich library materials and Chinese and foreign databases and platforms, which provide the material basis and the information resources for the scientific and technological innovation and the training of the innovative talents[2].

\section{SIGNIFICANT POSITION OF THE SCIENTIFIC AND TECHNOLOGICAL RESOURCES OF COLLEGES AND UNIVERSITIES IN SCIENTIFIC AND TECHNOLOGICAL INNOVATION}

As the combination of the first productivity of science and technology and the first resource of talents, colleges and universities play a vital role in scientific and technological innovation. Scientific and technological innovation is the creation, processing, disposing, dissemination and application of knowledge and information. Colleges and universities with the three functions of teaching, scientific research and social services are the organizations that can integrate the characteristics of the scientific and technological innovation, and the scientific and technological resources of colleges and universities are the guarantee and basis for the exertion of their functions. The role that the scientific and technological resources of colleges and universities play in scientific and technological innovation can be embodied in the following aspects:

\subsection{Innovative Talents Are the Core Resources of Scientific and Technological Innovation}

Colleges and universities have the largest, highlevel, outstanding talent pool in China. According to Table 1 (data source: Statistical Data Manual of the Scientific Research in Colleges and Universities of Guangdong Province in 2019), Sun Yat-sen University has invested the most in scientific and technological human resources, and Shenzhen Polytechnic has the most abundant scientific and technological human resources in higher vocational colleges.

Table 1. Statistics of science and technology human resources in some universities in Guangdong Province in 2019

\begin{tabular}{|l|l|l|l|}
\hline Name of the entity & Total research manpower & Total senior titles & The total number of Dr. \\
\hline Sun Yat-sen University & 6311 & 4001 & 5084 \\
\hline Shenzhen University & 4037 & 1344 & 3009 \\
\hline Jinan University & 3889 & 1437 & 2393 \\
\hline South China University of Technology & 3756 & 2220 & 2535 \\
\hline South China Normal University & 3175 & 1677 & 1880 \\
\hline South China Agricultural University & 3116 & 1282 & 1183 \\
\hline Guangdong University of Technology & 2999 & 1084 & 1254 \\
\hline Guangzhou University & 2676 & 1315 & 1459 \\
\hline Southern Medical University & 2175 & 539 & 722 \\
\hline Shenzhen Polytechnic & 1918 & 838 & 391 \\
\hline
\end{tabular}


Colleges and universities are the main training places for the talents needed in scientific and technological innovation, and the students trained by colleges and universities are the most active new forces for scientific and technological innovation. The demands for innovative talents in scientific and technological innovation are highly matched with the excellent talent resources and basic functions of colleges and universities, which determines that colleges and universities have an irreplaceable position in scientific and technological innovation [3].

\subsection{Innovative Activities Are the Core of Scientific and Technological Innovation}

Scientific and technological resources are most concentrated in the organizations of colleges and universities, which is conducive to carrying out various innovative activities as well as stimulating and generating creativity and innovation. Scientific research is the most important functional field of the scientific and technological activities of innovation in colleges and universities, while colleges and universities can not only provide the atmosphere of engaging in scientific research, but also have the basis of scientific and technological resources. In addition, various disciplines and multiple categories are interconnected in colleges and universities, which is conducive to implementing major innovative activities. In terms of scientific research projects, colleges and universities undertake a large number of national projects. For example, Sun Yat-sen University undertook seven items of "the 973 project" and 31 national key fund projects in 2019. As to the application of patents and the publication of papers, South China University of Technology applied for 3,721 patents, authorized 2,164 patents, and published 7,147 papers in the three major databases, ranking first among the universities in the GuangdongHong Kong-Macao Greater Bay Area. Speaking of the internal expenditure of the R \& D funds, Sun Yat-sen University was far ahead of other colleges and universities with 3.682 billion yuan in 2019[4].

\subsection{Colleges and Universities Are the Significant Subjects of Promoting the Collaborative Innovation}

The advantages of scientific and technological resources in colleges and universities are the growth points and radiation sources of the innovation in colleges and universities. Colleges and universities can improve their own scientific and technological innovation abilities and realize the marketization and socialization of resources by combining their own resources with the social economy. Meanwhile, they can mobilize the enthusiasm and creativity of other social subjects of innovation to provide support for scientific and technological innovation. For example, in 2019,
South China University of Technology signed 180 technology transfer contracts, with the highest real income of technology transfer at about 80.685 million yuan; Jinan University had the highest amount of contracts of transfer of technology, about 440 million yuan. Both universities are very competitive in technology transfer. Among the numerous universities, Sun Yat-sen University is most closely linked with other social units, with 606 staff members dispatched while accepting 270 members for cooperative research. In the critical period of social and economic transformation, the overall sharing of the scientific and technological resources in colleges and universities is essential to meet the needs of enterprises in connection with the scientific and technological innovation of colleges and universities and to improve their own abilities of scientific and technological innovation and social services [5].

\section{MAIN PROBLEMS THAT RESTRICT THE TRANSFORMATION OF THE SCIENTIFIC AND TECHNOLOGICAL RESOURCES IN COLLEGES AND UNIVERSITIES INTO INNOVATION}

Currently, the scientific and technological resources in colleges and universities are being severely scattered and inefficient, which leads to weak links and deepseated problems in the transformation of the scientific and technological resources in colleges and universities into innovation.

\subsection{The Collaborative Effectiveness of the Scientific and Technological Resources of the Government, Industries, Universities and Research Is Relatively Low}

The scientific and technological resources of innovation in colleges and universities should participate in the scientific and technological activities of innovation. The resource linkage should be carried with other innovative subjects, all of which are mainly manifested in the opening up, coordination and sharing of the scientific and technological resources among the government, industries, universities and research, so that the scientific and technological resources can be effectively aggregated under the leadership of the overall goal of innovation, and realize the in-depth cooperation and the open innovation among the government, industries, universities and research [6]. However, the role of the relevant departments in Guangdong Province in the macro guidance and incentive of science and technology has not been fully exerted, while they've been too much involved in the micromanagement of the supervision of the scientific and technological funds and the inspection of the projects of the scientific research with too careful 
control, which is not conducive to the independent decision-making and collaborative cooperation of colleges and universities according to the actual situation of the scientific research and market demands. In a lack of power and the negative lists, colleges and universities do not know what to do and what cannot do, resulting in the absence of linkage among the government, industries, universities and research. The innovation resources of the innovative subjects, such as colleges and universities, are divided into different links of the innovation chain, and the effective aggregation and allocation cannot be realized in the scientific and technological resources.

\subsection{The Mechanism of the Overall Sharing of the Scientific and Technological Resources in Colleges and Universities Should be Improved}

As an essential management subject of the scientific and technological resources, colleges and universities are not only the important incubation bases of the innovative resources such as science and technology and talents, but also the significant sources of the scientific and technological resources. However, due to the lack of top-level overall planning, there has been a system of their own in the construction of the scientific and technological resources of colleges and universities, the layout of which is relatively dispersed, while there is low-level redundant construction, and the allocation of the scientific and technological resources still needs to be further optimized[7]. As of June 2021, there were 38 public undergraduate colleges and universities in Guangdong Province, four cooperative colleges and universities between China and foreign countries (including the mainland, Hong Kong, Macao and Taiwan), 20 private undergraduate colleges and universities, five independent colleges, 67 public higher vocational colleges and 26 private higher vocational colleges. Even the public undergraduate colleges and universities had 1,616 research institutions at all levels. The average annual effective working hours per (set of) large-scale scientific research instrument and equipment was 1335.44 h. Among them, the large-scale instruments and equipment with annual effective working hours less than $960 \mathrm{~h}$ accounted for 56.13\%; in contrast, the average annual effective time of large-scale scientific research instruments in developed countries is between 2,700 and $3,200 \mathrm{~h}$. In the pattern of the scattered scientific and technological resources in colleges and universities, there is a lack of contact channels among colleges and universities. Among industries, universities and research, the channels for the flow of scientific and technological resources are not smooth. The sharing degree of the scientific and technological resources in colleges and universities is not high. Colleges and universities are different from scientific research institutes, enterprises and industries, social organizations and other stakeholders, and their value objectives are also quite different. There is a lack of motivation and a long-term mechanism for the collaborative innovation between colleges and universities, colleges and institutions, schools and enterprises, and schools and local entities. Although the situation has been improved in the context of collaborative innovation, there are still some problems in the allocation of scientific and technological resources among colleges and universities, enterprises, research institutes and other subjects, such as the institutional constraints, the insufficient communication between colleges and universities and other subjects, the unreasonable distribution of interests and the lack of the mechanism of coordination and supervision. Therefore, the resource-sharing platforms that can effectively integrate the linkage mechanisms with the smooth operation have not been formed. There is still a lack of the long-term, comprehensive and in-depth cooperation of industries, universities and research, and collaborative innovation.

\subsection{There Are Institutional Barriers in the Transformation of the Scientific and Technological Achievements of Colleges and Universities}

In the form of the government-led scientific and technological innovation in colleges and universities, the government finances the construction of the scientific and technological resources in colleges and universities, and provides special scientific research funds to support the scientific research projects which are needed for the economic and social development, so as to promote the docking of the scientific and technological resources in colleges and universities with the market demands. In the form of the scientific and technological innovation of the self-led type, universities and colleges use their own scientific and technological resources to carry out the activities of scientific and technological innovation by selecting topics independently. According to the Statistical Bulletin on Science and Technology / Social Science of Colleges and Universities in Guangdong Province in 2020 , there were 42,904 patents in public undergraduate colleges and universities in 2020, including 24,157 patents for invention in 2020; there were 560 contracts of transfer of technology in public undergraduate colleges and universities, the amount of which was 299.934 million yuan in sum, with an actual income of 220.623 million yuan in 2020. The two forms of scientific and technological innovation in colleges and universities have effectively promoted the combination of the scientific and technological resources in colleges and universities with the education and economy. However, the scientific and technological achievements have been treated as the state-owned assets in the corresponding transformation, while the colleges and universities had no right to dispose, get benefits from or 
control the achievements. As a result, the initiative and enthusiasm of transforming the scientific research achievements into productive forces are not high. There is the lack of the platform of public services for the transformation of the scientific and technological achievements of the colleges and universities in the Guangdong-Hong Kong-Macao Greater Bay Area, the existing relevant institutions fail to better play the role of the center of technological transfer, most universities have not set up the center of technological transfer on campus, and there is the lack of organization and planning for the transformation of technological achievements, all of which has seriously hindered the transformation of the scientific and technological achievements of colleges and universities in the Guangdong-Hong Kong-Macao Greater Bay Area.

\section{COUNTERMEASURES AND SUGGESTIONS ON THE TRANSFORMATION OF THE SCIENTIFIC AND TECHNOLOGICAL RESOURCES IN COLLEGES AND UNIVERSITIES INTO INNOVATIONS}

\subsection{Reinforcing the Collaborative Innovation of the Government-Industry-University- Research Resources}

The sharing of the government-industry-universityinstitute scientific and technological resources should be promoted. It is necessary to give full play to the guiding role of the government and the regulatory role of the market under the regulation of the market mechanism. We must also innovate the market-oriented services of the scientific and technological resources in colleges and universities, explore the cooperative mode of the scientific and technological innovation between colleges and universities and enterprises, coordinate the distribution of interests and the risk-taking relationship of each innovative subject, and give full play to the resource advantages of the colleges and universities in the research and development links, such as talents, technology and experimental equipment, as well as the advantages of enterprises in the capital, technological transformation and market [8]. The government should give full play to the role of organization, coordination and guidance in promoting the linkage of the government-industry-university-research cooperation of scientific and technological resources, designate specialized agencies or personnel to coordinate the government-industry-university-research collaboration, build a bridge between universities and enterprises, and guide the linkage of the scientific and technological resources of government-industry-university-research cooperation through relevant policies.

\subsection{Investigating and Improving the Sharing Mechanism of the Scientific and Technological Resources}

It is clearly stated in the Outline Development Plan for the Guangdong-Hong Kong-Macao Greater Bay Area that "to progressively open up to Hong Kong and Macao the major national R \& D infrastructure facilities and large-scale national $\mathrm{R} \& \mathrm{D}$ equipment located in Guangdong." Colleges and universities should fully explore and utilize the existing scientific and technological resources, actively open up the sharing, integrate with the complementary scientific and technological resources according to the needs of the activities of scientific and technological innovation, change the situation of dispersion into aggregation, and change the state of idleness into usefulness, so as to ensure the effective use of the existing scientific and technological resources[9]. The rules and regulations issued by the government should be used to clarify the system and procedures of the opening up of the sharing of scientific and technological resources of innovation, strengthen the opening up and the sharing of the platforms of innovation, the scientific and technological instruments and the information equipment, and improve the institutional level of the integration of the public services and the application of scientific and technological resources. With the help of the existing trading market of technologies and the platforms of the exchange of talents, the strength of the scientific and technological resources in colleges and universities should be made public to the society, and the channels for sharing the scientific and technological resources in colleges and universities to the society should be established to realize the extension of the services of the scientific and technological resources in colleges and universities to the society.

\subsection{Optimizing the Institution and Mechanism of the Transformation of the Scientific and Technological Achievements in Colleges and Universities}

By building a platform for the transformation of the scientific and technological achievements of the colleges and universities in the Guangdong-Hong KongMacao Greater Bay Area, colleges and universities in various regions can share the resources of large-scale apparatus and equipment, books and literature, and scientific and technological achievements, and open the resources of scientific and technological achievements to the public. It is necessary to adopt a government-led and market-oriented approach, make overall use of the scientific and technological resources of innovation in colleges and universities, improve the system and mechanism of innovative cooperation, optimize the development model of cross-regional cooperation and 
innovation, build an internationalized and open system of regional innovation, continuously improve the level and efficiency of the transformation of scientific research achievements, and accelerate the formation of the development model with innovation as the main guide and support [10].

\section{CONCLUSION}

With the in-depth implementation of the innovationdriven development strategy in China, Guangdong's experiment of comprehensive innovation and reforms has been steadily promoted, and the construction of the demonstration zones of independent national innovation has been accelerated. The abilities of research and development and the capacities of transformation of the colleges and universities in Guangdong, Hong Kong and Macao are prominent. The attractiveness of their innovation factors is strong, which will radiatively drive the scientific and technological development of the innovation of the whole Guangdong-Hong Kong-Macao Greater Bay Area in the future. In the investments of the scientific and technological resources, each government department in the Guangdong-Hong Kong-Macao Greater Bay Area should fully consider the distribution pattern of the scientific and technological resources in colleges and universities, make overall planning, and adhere to the guidance of policies and the innovation of management under the guidance of innovation to give full play to the maximum utility of the limited resources. Colleges and universities should also actively integrate into the economic, technological and innovative development and construction of the Guangdong-Hong Kong-Macao Greater Bay Area, improve their capabilities of innovation and their level of the transformation of scientific and technological achievements, so as to enhance the level of the scientific and technological collaborative innovation in the entire Guangdong-Hong Kong-Macao Greater Bay Area.

\section{ACKNOWLEDGMENTS}

This paper is a research project of Guangdong Provincial Education Science "Thirteenth Five-Year Plan” in 2020 (2020GXJK247), and one of the milestones of the "Double-high Plan" project (SG03-02.6) of Guangdong Food and Drug Vocational College.

\section{REFERENCES}

[1] Zhang WH. Problems and countermeasures of the innovative transformation of the scientific and technological resources in colleges and universities. Tianjin Science \& Technology. 2014 Sep. 25; 1006-8945; 7-10.
[2] Jiang YP. System and mechanism reform of the optimal allocation of the scientific and technological resources in the colleges and universities of Guangdong Province. Science and Technology Management Research. 2016 May 10; 1000-7695; 116-119.

[3] Chen ShM. The sharing status and countermeasures of the large-scale scientific research instruments in Guangdong Province. Research and Exploration in Laboratory. 2021 Feb. 25; 1006-7167; 266-269.

[4] Zhu L. The analysis and enlightenment of the sharing status of large-scale scientific research instruments in South China. China Science \& Technology Resources Review. 2019 Mar. 28; 1674-1544; 1-8.

[5] Yan B. Current situation, problems and countermeasures of the collaborative innovation of science and technology in the PRD region. Science and Technology Management Research. 2019 Jan. $10 ; 1000-7695 ; 87-96$.

[6] Liu Yang, Wei Wenqiu, Feng Chunsheng, Lin Xiong. (2019) Research on the Status, Problems and Countermeasures of Transformation of Scientific and Technological Achievements in Universities and Research Institutes in Guangdong Province. Science and Technology Management Research, 39(02): 91-97.

[7] Yuan Chuansi, Jia Xiao, Yuan Lixin. (2020) Exploratory Research on the Implementation Modes and Paths of Transformation of Scientific and Technological Achievements in Universities. Science and Technology Management Research, 40(03): 84-89.

[8] Jiang Hai, Zi Hongzhi. (2015) Exploration and Practice of Collaborative Innovation Model for Transformation of Scientific and Technological Achievements in Universities in Guangdong. Science and Technology Management Research, 35(16): 94-99.

[9] Hu, Shujuan. (2019) Research on the Current Problems and Countermeasures of Patent Transformation in Research Institutes of Universities in Qinghai Province. Science \& Technology Information, 17(12): 186-188.

[10] Zhong Jiatao. (2016) Adopting Information Technology Means to Enhance the Effective Use of Technical Resources in the Transformation of Scientific and Technological Achievements. Modern Industrial Economy and Informationization, 16: 95-97. 